\title{
ANALYSIS OF EARTHQUAKES RECORDINGS OF TIDAL GRAVIMETERS IN THE PERIOD RANGE OF 10-1000 s
}

\section{Kamila KARKOWSKA ${ }^{1,2)}$ *, Monika WILDE-PIÓRKO ${ }^{1 \text { ) }}$ and Przemyslaw DYKOWSKI ${ }^{1)}$}

\author{
1) Institute of Geodesy and Cartography, Centre of Geodesy and Geodynamics, Warsaw, Poland \\ 2) Warsaw University of Technology, Faculty of Geodesy and Cartography, Warsaw, Poland
}

*Corresponding author's e-mail: kamila.karkowska@igik.edu.pl

\begin{tabular}{l} 
ARTICLE INFO \\
\hline Article history: \\
Received 18 October 2021 \\
Accepted 7 December 2021 \\
Available online 21 December 2021 \\
\hline
\end{tabular}

Keywords:

Gravimeter

Seismometer

Transfer function

Earthquake

Rayleigh wave

\section{ABSTRACT}

The physical properties of tidal gravimetric instruments allow recording, not only tidal effects, but also waves generated by earthquakes. Three gravimetric stations with determined transfer functions and co-located seismic stations from the observatories in Western and Central Europe were selected for analysis. The observatories are equipped with almost all types of sensors available on the market, which allow for thorough analysis of earthquake recordings in the period range of 10-1000 s. In total, over 10,000 traces of worldwide earthquakes were investigated. The saturation levels of gravimeters as well as a correlation between the gravimetric and seismometric signals of an earthquake were carefully analysed. A simple processing scheme of gravimetric signal of earthquakes was adopted thanks to the probabilistic power spectral density analysis of continuous recordings. The detail analysis of transfer function of gravimeters allowed to define a period range when a sensitivity coefficient (calibration factor) and a time lag value only can be used to properly describe the properties of instruments. What's more, it has been shown based on the calculated group-velocity dispersion curves of fundamental mode of Rayleigh waves, that the Earth's mantle structure can be determined for greater depths from the recording of tidal gravimeters than from typical broad-band seismometers.

\section{INTRODUCTION}

In the 20th century, gravimetric recordings were typically used in tidal studies or in analysis of the Earth's free oscillations. Still, nowadays, superconducting gravimeter (SG), with its unprecedented precision, allows monitoring of many systems, such as hydrogeological, hydrothermal, postseismic and post-glacial relaxation or volcanoes (Van Camp et al., 2017).

In 1975, the first station of IDA (International Deployment of Accelerometers) project was installed. Soon it became one of twenty worldwide distributed stations (Agnew et al., 1986) of a global digital seismic network that measured ground motion at very long periods ( $\mathrm{T} \geq 60 \mathrm{~s}$ ). The measuring system design was based on LaCoste\&Romberg gravimeters converted to long-period seismic sensors. The number of stations in the network was determined by the typical wavelengths of seismic waves at normal mode frequencies. A cross-spectral calibration procedure (Berger et al., 1979) was developed to make it possible to calibrate the system with $1 \%$ accuracy. Analyses of IDA data have led to e.g. better models of anelasticity of the Earth (e.g. Masters et al., 1982), the determination of the worldwide distribution of group velocity of mantle Rayleigh waves (Nakanishi and Anderson, 1982), and reliable estimation of the source mechanism at long periods (Kanamori and Given, 1981).

The wide range of frequencies recorded by present relative gravimeters allows using their recordings to analyse tidal periods and geophysical phenomena. The performance of gravimeters in the seismic frequency band has been studied by e.g., Kamal and Mansinha (1992), Freybourger et al. (1997), Banka and Crossley (1999), Rosat et al. (2004), Forbriger et al. (2021) by examining the power spectral density of noise levels of those instruments. Furthermore, Richter et al. (1995) and Freybourger et al. (1997) carried out a comparative study of tidal gravimeters and very broad-band (VBB) and broad-band $(\mathrm{BB})$ seismometers in seismic frequency bands by analysing the normal modes after the Bolivian earthquake of 9 June 1994. The seismic normal modes recorded by the tidal gravimeters after the largest earthquakes were also analysed by e.g. Van Camp (1999), Widmer-Schnidrig (2003), Rosat et al. (2005), and Niebauer et al. (2011). Li et al. (2020) recently extracted long-period surface waves and free oscillations using ambient noise recorded by globally distributed SGs. These studies showed that gravimeters had proven their effectiveness in the research related to the normal mode and Earth's free oscillation frequency band. 
Gravimeters and seismometers are inertial sensors, and so both are sensitive to acceleration. For any ground motion above the noise level and below the saturation level, either system will provide the same information (though perhaps with a different signal to noise level). Widmer-Schindrig (2003) and Forbriger et al. (2021) have shown that under exceptional site conditions at the Black Forest Observatory, the noise level of GWR SG-056 superconducting gravimeter (upper sphere) is slightly above the noise level of STS-1 seismometer for periods longer than $1000 \mathrm{~s}$. However, the amplitude of surface waves of the largest earthquakes can exceed the dynamic range of SG.

Various data processing schemes were so far used for researchers analysing gravimetric recordings and comparing them with seismometric ones in the seismic frequencies band.

Niebauer et al. (2011) have compared recordings of a magnitude of 8.2 earthquake from Kuril Islands (January 2007) from a g Phone gravimeter, a superconducting gravimeter as well as a BB seismometer (STS-2) in Walferdange, Luxemburg. They integrated the gravity data to yield velocity and compared it with the vertical component data of STS-2. The scale of the STS-2 data was normalized to the gravimeter data because the gravimeters' scale factors were known with higher precision. The authors observed a very good agreement between the recordings of the instruments. Furthermore, a g Phone showed more Rayleigh wave arrivals; at least 11 separate arrivals were noted. However, the correlation was not so good for longer periods because the transfer function of the STS-2 seismometer was not taken into consideration.

Richter et al. (1995), in their comparison of cryogenic gravimeters and other instruments in a wide period range, among others, compared recordings of relative gravimeters ( $\mathrm{SG}$ and spring gravimeter) and VBB and BB seismometers (STS-1 and STS-2) in a period range of 768-4020 s. They mentioned that the transfer function of the GWR gravimeter is not very well known and not necessary to be applied in the analysed periods' range. Hence, they compared the performances of instruments by comparing the signalto-noise ratios (SNR) in a selected period band without correcting for the instrumental responses.

Banka and Crossley (1999), in their research on the noise levels of SGs at seismic frequencies, confirmed that the air pressure can affect noise in the normal seismic mode band (60-3240 s) and that the air pressure correction is more important where the site and instrument qualities are high. They have also shown that neglecting that correction did not significantly change the noise estimates. So, only where the air pressure data were available, its correlation with gravity was high, and the admittance was reasonable, they applied an air pressure correction.
Freybourger et al. (1997) have found that at periods lower than $2500 \mathrm{~s}$, no difference was visible between power spectral density values of SG records from the J9 station near Strasbourg, without and with air pressure correction estimated by a simple linear coefficient. More complex air pressure correction with time-dependent phase shift and amplitude coefficients was estimated for VBB seismometers in the seismic band by Beauduin et al. (1996). The coherence between the horizontal components of seismic data and the atmospheric pressure field was observed to be very high for periods larger than $33 \mathrm{~s}$. In comparison, the vertical components of the seismic noise were correlated to the atmospheric pressure change only in a period range of 500-3333 s.

Zürn and Meurers (2009) have presented a careful analysis of the influence of the atmosphere on gravity measurements at periods below $1000 \mathrm{~s}$. They have demonstrated that the gravitational effect and the free air/inertial effects due to deformation have the opposite sign. Furthermore, the inertial effect is strongly frequency-dependent, so near frequencies of a few $\mathrm{mHz}$ the air pressure effect on gravity recordings changes sign and amplifies the gravity residuals' variance reduction. Peterson (1993) shows in his studies of broad-band seismic noise at many stations of the Global Seismic Network that the lower envelope of vertical acceleration noise power spectral densities has a minimum near $333 \mathrm{~s}$, which is not observed in the horizontal components. Van Camp et al. (2017) have summed up that at periods larger than $500 \mathrm{~s}$, the Newtonian attraction of moving air masses in the local atmosphere above the gravity and seismic sensors is the principal source of the noise in the seismic frequency band. They also have noted that the atmospheric pressure coefficient is often close to $-3.0 \mathrm{~nm} / \mathrm{s}^{2} / \mathrm{hPa}$ for longer periods but drops down to zero at $500-1000 \mathrm{~s}$.

The authors of the presented research have examined over 10,000 traces of worldwide earthquakes recorded by various types of tidal gravimeters and co-located VBB and BB seismometers. For the first time, thanks to such large database, a thorough estimation of the quality of earthquake recordings made by tidal gravimeters in the period range of 10-1000 s was carried out. The saturation level of gravimeters, as well as correlation between the gravimetric and seismometric signals of earthquakes, especially for selected wave trains were carefully analysed. Probabilistic power spectral density analysis of continuous recordings of instruments allowed to verify the data processing schemes proposed by other authors and to suggest a new simple processing scheme of gravimetric signal of earthquakes in the analysed period range. A period range when a sensitivity coefficient (calibration factor) and a time lag value only can be used to properly describe the properties of gravimeters has also been estimated for the first time. Finally, groupvelocity dispersion curves of the fundamental mode of Rayleigh waves were estimated to demonstrate more 
Table 1 List of gravimeters and seismometers with coordinates of their location, analysed time interval of data and instrument types with the corresponding station and channel codes. All data was downloaded from the IRIS database.

\begin{tabular}{|c|c|c|c|c|c|c|c|}
\hline Site & $\begin{array}{c}\text { Latitude } \\
\text { [degrees] }\end{array}$ & $\begin{array}{l}\text { Longitude } \\
\text { [degrees] }\end{array}$ & $\begin{array}{c}\text { Analysed } \\
\text { time interval }\end{array}$ & \multicolumn{2}{|c|}{ Gravimeter } & \multicolumn{2}{|c|}{ Seismometer } \\
\hline \multirow[t]{2}{*}{ Black Forest } & \multirow[t]{2}{*}{48.3301} & \multirow[t]{2}{*}{8.3296} & \multirow{2}{*}{$\begin{array}{c}07.2013- \\
03.2020\end{array}$} & GWR SG-056 & $\begin{array}{l}\text { BFO.LG1 (L) } \\
\text { BFO.LG2 (U) }\end{array}$ & \multirow{2}{*}{$\begin{array}{c}\text { STS-1 } \\
\text { (VBB, } 360 \mathrm{~s})\end{array}$} & \multirow{2}{*}{$\begin{array}{l}\text { BFO. } \\
\text { BHZ }\end{array}$} \\
\hline & & & & LCR ET-19 & BFO.LGZ & & \\
\hline Membach & 50.6092 & 6.0067 & $\begin{array}{c}07.2013- \\
03.2020 \\
\end{array}$ & GWR C021 & MEMB.LGZ & $\begin{array}{c}\text { CMG3T } \\
(\mathrm{BB}, 30 \mathrm{~s})\end{array}$ & $\begin{array}{l}\text { MEM. } \\
\text { HHZ }\end{array}$ \\
\hline Rochefort & 50.155 & 5.2260 & $\begin{array}{c}06.2017- \\
03.2020\end{array}$ & $\begin{array}{c}\text { GWR iGrav } \\
019\end{array}$ & RCHS.LGZ & $\begin{array}{c}\text { Trillium } \\
\text { Compact } \\
(\mathrm{BB}, 120 \mathrm{~s})\end{array}$ & $\begin{array}{l}\text { RCHB. } \\
\text { HHZ }\end{array}$ \\
\hline
\end{tabular}

accurately capabilities of various instruments for the determination of the Earth's mantle structure. Tidal gravimeters, especially superconducting ones, can provide earthquake recordings of higher quality than typical BB seismometers (except for STS-1), so the gravimetric recordings of earthquakes can be complementary to the seismometric ones.

\section{DATA}

Data recorded by co-located tidal gravimeters and $\mathrm{VBB}$ and $\mathrm{BB}$ seismometers (only vertical component) were analysed. Time series from tidal gravimeters are available in the International Geodynamics and Earth Tide Service (IGETS) database, while seismometer's data can be downloaded from e.g. Incorporated Research Institutions for Seismology (IRIS) database. The latter database also includes gravimetric data together with full transfer functions of instruments from a few observatories, i.e. Black Forest Observatory and Royal Observatory of Belgium. The period range of 10 $1000 \mathrm{~s}$ was considered to analyse the potential of tidal gravimeters in the study of the ground motion, primarily generated by the earthquakes.

\subsection{DATA SELECTION}

Four criteria were set for data selection. The first criterion (1) was the co-location of gravimeter and seismometer sensors. Therefore, the differences between the recordings do not result from different locations of the instruments but they are directly related to the sensitivity of the sensors in a particular range of periods. The second criterion (2) was the accessibility of $1 \mathrm{~Hz}$ gravimetric data, which is not typical for IGETS stations, for which customarily 1-minute data are available. The third one (3) was the accessibility of the full transfer function for the gravimeters to recover the actual ground motion and make it comparable to the recordings of the seismometers. Only selected observatories evaluate and provide the full transfer function for their gravimeters. In the IGETS database usually, only a calibration coefficient is given. Station operators can provide also a time lag of the gravimeter, but its value may not be very accurate or may be suggested by the manufacturer without being empirically determined.
The last criterion (4) was an easy access to a significant amount of data and the instruments' transfer function.

Only three observatories met the above criteria: one in Germany (Black Forest - BFO) and two in Belgium (Membach - MEM, and Rochefort - RCHB). The data was downloaded from the IRIS database (http://ds.iris.edu/ds/nodes/dmc/data/types/waveform -data/, last accessed 4 January 2021). The stations are equipped with various types of gravimetric instruments, i.e. single and dual sphere SGs and a spring gravimeter, and various types of seismic instruments, i.e. VBB and $\mathrm{BB}(30 \mathrm{~s}$ and $120 \mathrm{~s})$ seismometers. A summary of sensors type together with the analysed time interval is presented in Table 1.

In the analysed time interval, the continuity of recorded gravimetric signals was at the level of 99.85 \% (BFO.LG1/2), 99.44 \% (BFO.LGZ), $99.23 \%$ (MEMB.LGZ) and $98.13 \%$ (RCHS.LGZ), while the one of seismometric signals was at the level of 99.61\% (BFO.BHZ), 99.09\% (MEM.HHZ) and $84.10 \%$ (RCHB.HHZ).

\subsection{TRANSFER FUNCTION}

Wenzel (1994) and Van Camp et al. (2000), in the nineties of $20^{\text {th }}$ century, developed methods for experimental determination of the phase lags using the step response and injected sine waves procedures. Francis et al. (2011) have compared transfer functions of three SGs and proved that transfer function is unique for each instrument. They also noted that the transfer function of SGs is crucial to use their records entirely.

In contrast to the transfer function, which is known only for a limited number of gravimeters, the calibration factor (equivalent to the sensitivity coefficient of the transfer function) is determined for every instrument. SGs should be calibrated with the accuracy of $0.1 \%$ in amplitude and 0.01 second in phase to reach optimal performance for tidal analysis (Francis et al., 2011).

Amplitudes of transfer functions and phase delays (calculated based on phase of the transfer function) of analysed instruments are presented in Figure 1. The value of the phase delay of gravimeters increases with growing period and then stabilizes at 


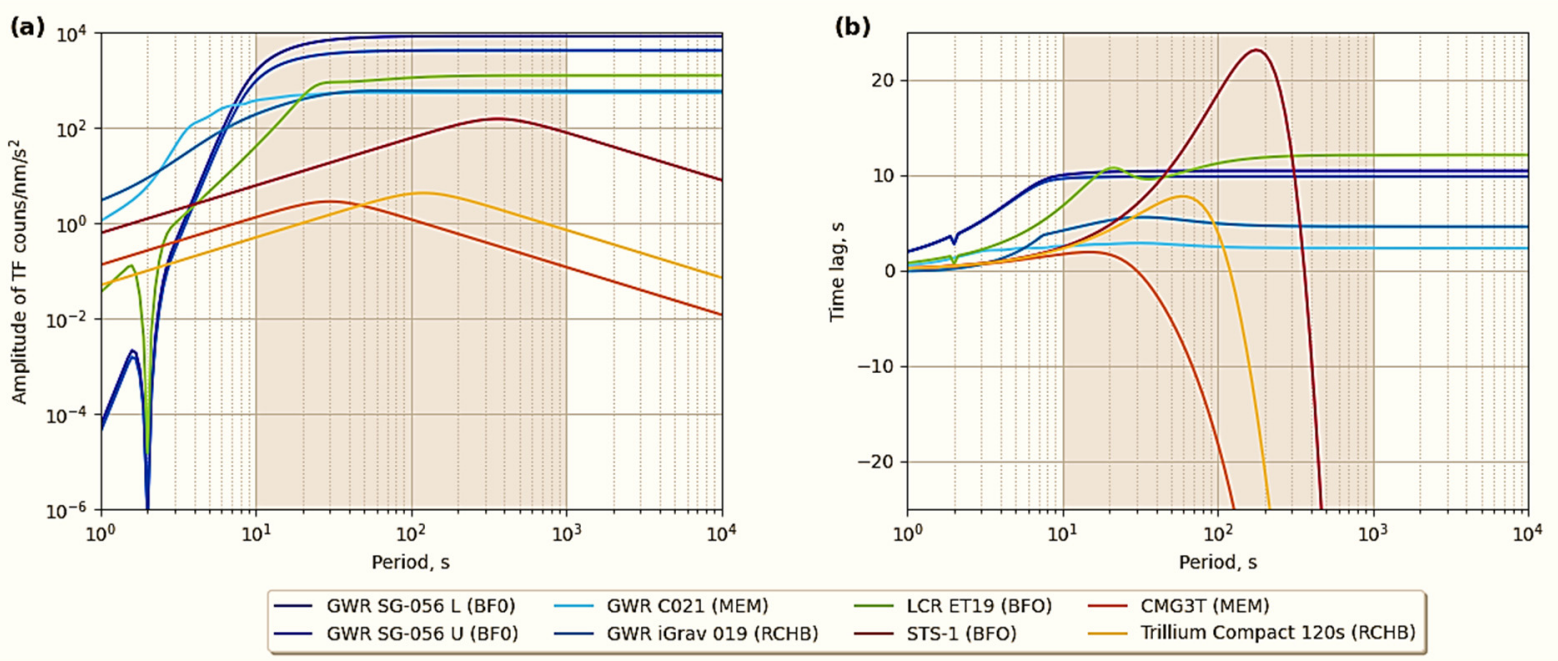

Fig. 1 The amplitude of the transfer function (a) and phase delay (b) values for SGs (lines in shades of blue), spring gravimeter (green line) and the VBB (red line) and BB seismometers (lines in shades of orange). Gray shaded areas correspond to the analysed period range of 10-1000 s.

a specific value that depends on the instrument, e.g. the phase delay curve for MEMB.LGZ is consistent with that determined by Van Camp et al. (2008) and converges to $2.4 \mathrm{~s}$. In the case of seismometers, this parameter rises sharply, reaches a maximum, and then drops rapidly with growing period. In tidal fitting programs (such as ETERNA by Schueller, 2019), a group delay should be considered to estimate theoretical tides at a station. When a linear phase condition is fulfilled, the phase and group delay values of a system are constant and equal. That is true for the considered channels of gravimeters for a period exceeding $200 \mathrm{~s}$ (codes of channels depending on sampling rate and response band of instrument, instrument type and orientation). So, later in the text, the term 'time lag' is used as a synonym for group delay of systems (on the assumption that the group delay is equal to the phase delay for a period exceeding $200 \mathrm{~s})$.

In the presented plots it can be well seen that amplitudes and phases of waves recorded by gravimetric and seismic stations can be distorted in the analysed period range of 10-1000 s (grey shaded areas in Figure 1). Hence, the gravimetric and seismometric data should be corrected for their transfer functions. However, because of the characteristics (shape) of the gravimeter transfer functions, it is justified for an accurate description of the instrument to use only sensitivity coefficient and time lag value for periods exceeding $200 \mathrm{~s}$. That fact will be confirmed later during the multiple-filtering procedure.

At the Black Forest Observatory, the SG is unique because of its double-sphere system. The lower sphere (GWR SG-056 L) has the same size as the upper one (GWR SG-056 U) but is heavier, i.e. $17.7 \mathrm{~g}$ compared to $4.34 \mathrm{~g}$ (Rosat and Hinderer, 2011). It can be seen that shapes of amplitudes and time lags curves for both spheres are very similar (Fig. 1a), but the spheres exhibit different sensitivity, i.e.
-8361.2 counts $/ \mathrm{nm} / \mathrm{s}^{2}$ for the lower sphere and -4185.0 counts $/ \mathrm{nm} / \mathrm{s}^{2}$ for the upper sphere.

\subsection{NOISE LEVELS COMPARISON}

The probabilistic power spectral densities (PPSD) of the recorded gravimetric and seismometric signals have been calculated based on the strategy proposed by McNamara and Buland (2004). PPSD has been computed by using a modified Welch periodogram on 1-day segments overlapping with $50 \%$. All data has been initially filtered with the bandpass zero-phase Butterworth filter in the period range of 5-10,000 s and then deconvolved with the transfer function of the instrument. Additionally, seismometric signals were resampled to $1 \mathrm{~Hz}$ and then differentiated. The data at this level of processing is called the initially pre-processed data. The effects of tides were calculated based on the potential catalogue of Tamura (1987) and the FES04 ocean tidal loading model (Bos and Scherneck, 2021) in ETERNA software (Schueller, 2019), and the local atmospheric pressure effect was computed with the standard coefficient of $-3.0 \mathrm{~nm} / \mathrm{s}^{2} / \mathrm{hPa}$. The PPSD analysis has been applied to each recorded signal for four cases: (1) initially pre-processed data, (2) initially pre-processed data with additional band-pass zero-phase Butterworth filtering of corner periods of 5 and $1000 \mathrm{~s}$, (3) initially pre-processed data after removing tides, (4) initially pre-processed data after removing tides and the local atmospheric pressure effect. Noise levels of instruments were determined as $5^{\text {th }}$ percentile of PPSD of recorded signals (Fig. 2).

The observed noise levels in the case (1) are dominated by local atmospheric pressure and tides for periods larger than $100 \mathrm{~s}$. Unfortunately, local atmospheric pressure corrections calculated using a single coefficient increase the observed energy in the period range of 100-600 s for the most sensitive instrument considered in this study, i.e. STS-1 

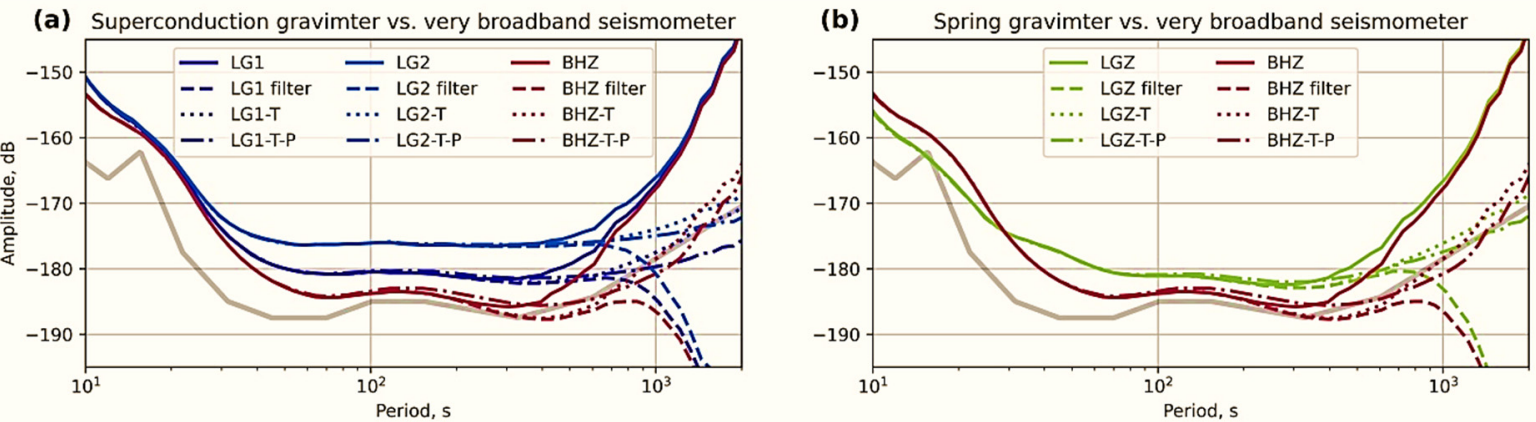

Fig. 2 Noise level of SG (LG1, LG2), spring gravimeter (LGZ) and VBB seismometer (BHZ) in Black Forest Observatory for four cases: (1) initially pre-processed data (solid line); (2) initially pre-processed data with additionally filtering in the period range of 5-1000 s ("filter", dashed line); (3) after subtraction of tides from the initially pre-processed data ("T", dotted line) and (4) after removing tides and the local atmospheric pressure effect from the initially pre-processed data ("T-P", dashed-dotted line). The NLNM (Peterson, 1993) has been plotted as the solid grey line.

(case 4). This effect is very slight for the lower sphere of GWR SG-056 gravimeter and is not observed for other investigated instruments because of the higher noise level of their systems. A similar feature in the period range of 800-960 s was observed by Rosat and Hinderer (2018) for the iGrav-029 gravimeter on a selected 15 days recordings. Also, Van Camp et al. (2017) mentioned that by applying a standard correction based on the atmospheric pressure record performed at the seismic and gravity stations it is possible to reduce the signal variance, only up to periods of about $600-900$ s. However, the analysis performed in this study shows that the application of the standard local atmospheric pressure correction in the period range of 10-1000 s can raise the variance of the data (dash-dotted lines in Figure 2). Therefore, application of standard corrections based on the local atmospheric pressure is not recommended. What's more, the lowest variance of the data can be observed for the case (2), when initially pre-processed data was additionally filtered with the band-pass zero-phase Butterworth filter of corner periods of 5 and $1000 \mathrm{~s}$.

\section{EARTHQUAKE RECORDINGS}

The database of earthquake recordings has been created for analysed gravimeters and seismometers data. First, the event window was selected based on the EMSC bulletin. Then, the recordings were preprocessed as follows: (1) the instrument response (transfer function) was removed together with detrending, tapering, and filtering of the signal; (2) the waveform was differentiated (only in the case of seismometric data to produce the accelerated signal); (3) a zero-phase bandpass Butterworth filter with corner frequencies of 10 and $1000 \mathrm{~s}$ was applied; (4) the data was resampled to $1 \mathrm{~Hz}$ (only in the case of seismometric data). The above-described procedure of data pre-processing was called the Transfer Function scheme (TF). Additionally, in the case of gravimetric data the Sensitivity Coefficient scheme (SEN) was applied, in which the sensitivity coefficient (the same for all frequencies) was used instead of the full transfer function to show the inaccuracies of the earthquake recordings of gravimeters in a commonly practiced approach.

The example of pre-processed recordings of the Nicaragua earthquake (2014-04-11 20:29:15.0 UTC, $11.72^{\circ} \mathrm{N}, 85.98^{\circ} \mathrm{W}$, depth $151 \mathrm{~km}$ ) from the Black Forest Observatory have shown an excellent consistency between seismometric and gravimetric signals for the TF scheme (Figures $3 \mathrm{~b}$ and $3 \mathrm{~d}$, correlation coefficient of 0.997). When only a sensitivity coefficient was applied (SEN scheme), a visible phase shift and amplitude difference was observed (Figures 3a and 3c, correlation coefficient of -0.856 ). What's more, a correlation coefficient is negative because the time lag of the signal is not included in the processing scheme.

The quality of gravimetric and seismic recordings of earthquakes were automatically verified based on the signal-to-noise ratio. Then, after the manual verification, the final list of events with visible seismic energy was created. In total, 1500-1800 events (except Rochefort with about 600 events) with magnitudes ranging from 3.6 to 8.3 and distances from the source from 450 to $18700 \mathrm{~km}$ were considered for each observatory.

Certain disadvantage of tidal gravimeters, especially superconducting ones, is the saturation of the recorded signal. The dynamic range of tidal gravimeters is small to track slight changes in the acceleration of gravity, so the signal from strong earthquakes can be saturated. The distribution of maximum values of amplitudes of earthquakes recorded by gravimeters and seismometers has shown that features of tidal gravimeter's signal very clearly (Fig. 4).

The SG gravimetric recordings are destroyed when amplitudes exceed $\pm 0.9 \cdot 10^{4} \mathrm{~nm} / \mathrm{s}^{2}$ (BFO.LG1) and $\pm 1.5 \cdot 10^{4} \mathrm{~nm} / \mathrm{s}^{2}$ (BFO.LG2, MEMB.LGZ and RCHS.LGZ). The earthquake signals of the LCR ET-19 spring gravimeter (BFO.LGZ) saturate in 

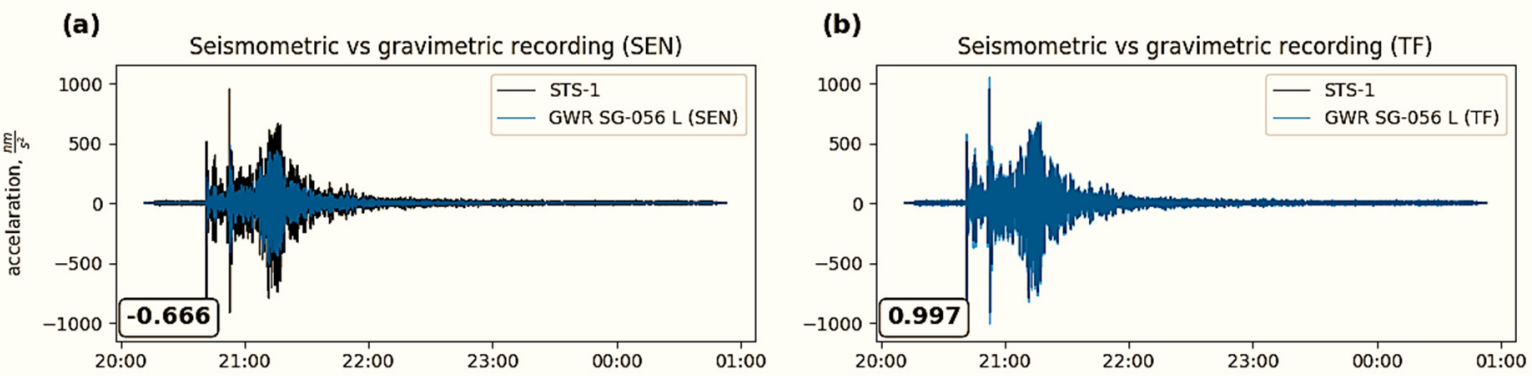

(c)

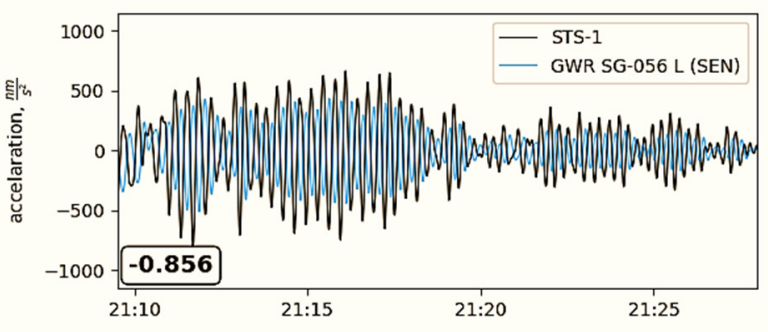

(d)

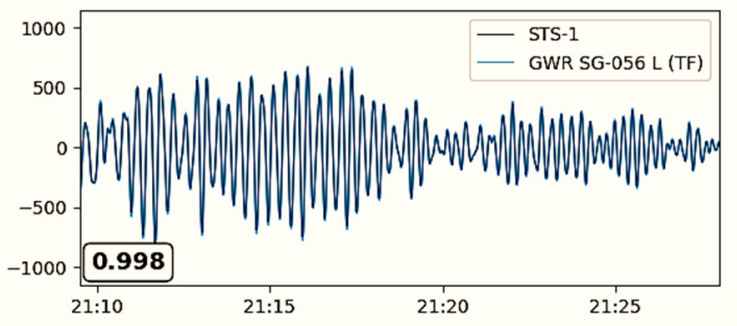

Fig. 3 Gravimetric (blue) vs. seismic (black) recordings of the M6.6 Nicaragua earthquake from the Black Forest Observatory for the SEN (a, c) and the TF (b, d) scheme. In the left bottom corners, a coefficient of correlation between seismometric and gravimetric data is shown.
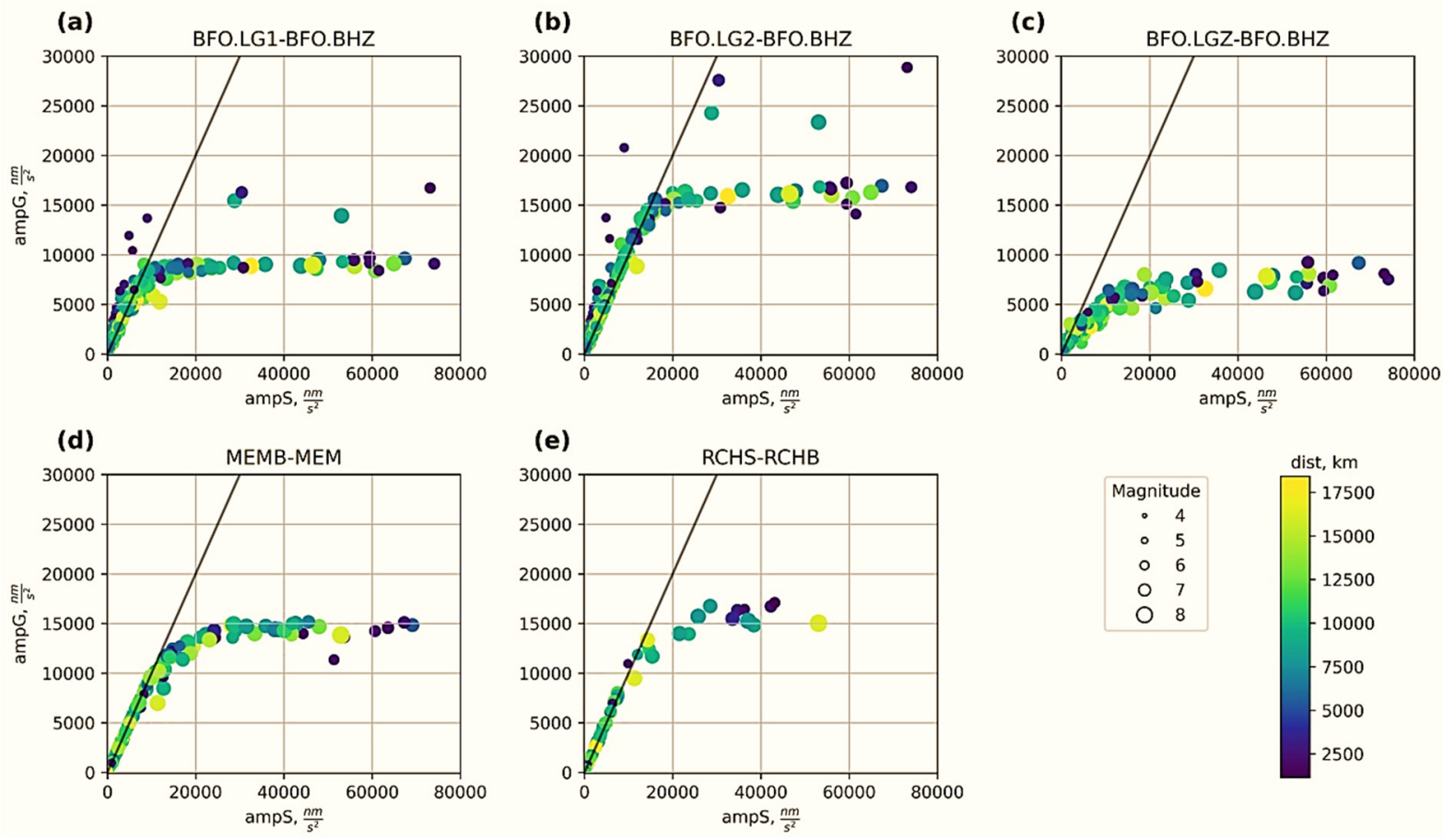

Fig. 4 Maximal amplitudes of earthquake recordings of the gravimeter and co-located seismometer at the Blake Forest (a-c), Membach (d) and Rochefort (e) stations. The size of circles corresponding to the magnitude of earthquakes, and colour - to the distance between source and station.

a wider range, i.e. from $\pm\left(1 \cdot 10^{4}-1.5 \cdot 10^{4}\right) \mathrm{nm} / \mathrm{s}^{2}$. The data were pre-processed with the TF scheme to avoid a distortion of saturated signal during the removing of gravimeter transfer function. The maximal amplitudes recorded by the Membach and Rochefort instruments were determined for data, which were additionally high-passed filtered with a corner period of $120 \mathrm{~s}$ and $360 \mathrm{~s}$, respectively, to avoid an overestimation of amplitudes of seismometric recordings for periods when the amplitude of their transfer function is close to zero. To be consistent with calculations for STS-1, the values of the corner period of those filters were chosen as 3 times of the long period corner of seismic sensors.

The waveforms from gravimetric records have been checked for saturation, and some entries have been removed from the database. Ultimately, the following number of events with magnitude in 


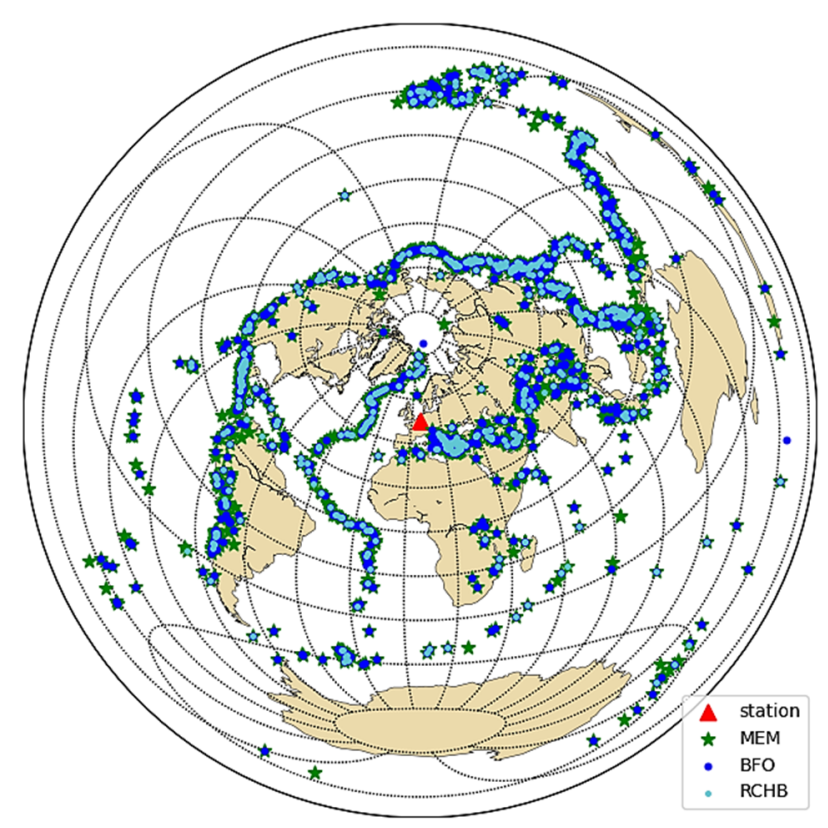

Fig. 5 Distribution of epicenters of earthquakes from the final database (codes refer to seismic stations).

Table 2 Statistics: mode of a sample (mode), mean, standard deviation (std), minimum (min) and maximum (max) values of correlation coefficient between gravimetric and co-located seismometric recordings of earthquakes for the TF and SEN schemes.

\begin{tabular}{|c|c|c|c|c|c|c|c|c|c|c|}
\hline \multirow{2}{*}{ Instruments } & \multicolumn{5}{|c|}{ TF } & \multicolumn{5}{|c|}{ SEN } \\
\hline & mode & mean & std & $\min$ & $\max$ & mode & mean & std & $\min$ & $\max$ \\
\hline BFO.LG1-BFO.BHZ & 0.99 & 0.90 & 0.33 & -0.82 & 1.0 & -0.66 & -0.43 & 0.32 & -0.90 & 0.63 \\
\hline BFO.LG2-BFO.BHZ & 0.99 & 0.90 & 0.34 & -0.82 & 1.0 & -0.78 & -0.45 & 0.35 & -0.93 & 0.77 \\
\hline BFO.LGZ-BFO.BHZ & 0.97 & 0.89 & 0.10 & 0.05 & 1.0 & -0.42 & -0.46 & 0.13 & -0.80 & -0.08 \\
\hline MEMB.LGZ-MEM.HHZ & 0.99 & 0.96 & 0.04 & 0.62 & 1.0 & 0.55 & 0.54 & 0.15 & 0.02 & 0.87 \\
\hline RCHS.LGZ-RCHB.HHZ & 0.95 & 0.75 & 0.34 & -0.76 & 1.0 & -0.02 & 0.05 & 0.22 & -0.66 & 0.99 \\
\hline
\end{tabular}

the range of 3.6-8.3 were selected for the entire observation period (a final database): 1408 (BFO.LG1), 1447 (BFO.LG2), 1465 (BFO.LGZ), 1706 (MEMB.LGZ) and 566 (RCHS.LGZ) for gravimetric signals, 1528 (BFO.BHZ), 1473 (MEM.HHZ) and 475 (RCHB.HHZ) for seismometric ones (Fig. 5). The summary of statistics of correlation coefficient of gravimetric and co-located seismometric recordings of earthquakes for the TF and SEN schemes are presented in Table 2. Examples of histogram of correlation coefficient for the selected gravimeter and co-located seismometer from the Black Forest and Membach observatories are shown in Figure 6. In order to calculate the correlation coefficients, the Membach and Rochefort data were additionally high-passed filtered with corner periods of $120 \mathrm{~s}$ and $360 \mathrm{~s}$, respectively. Low and negative values of the mode and mean of the coefficient of correlation in the SEN scheme are caused by not including the information about a phase of the gravimeter transfer function (a time lag) during the processing scheme.

The coefficients of correlation are very high (mode of sample above 0.94 ) in the TF scheme. So, when the observatory is not equipped with a BB seismometer, a tidal gravimeter can be used as a VBB seismometer (for periods exceeding $10 \mathrm{~s}$ ), or the tidal gravimeter can supplement $\mathrm{BB}$ seismometric data (e.g., for 30,60 , or 120 s sensors) in a long-period range.

In order to verify the possibility of supplementing seismometric recordings of earthquake with gravimetric data, 67 strong earthquakes have been examined in more detail for the SEN (i.e. only the sensitivity coefficient of gravimeter is known) and TF (i.e. full transfer function of gravimeter is known) schemes. The gravimetric and co-located seismometric recordings were filtered using the set of Gaussian filters with the filter coefficient linearly dependent on a period (100 central periods, between 10 and $1000 \mathrm{~s})$. Then, the coefficients of correlation between the gravimetric and co-located seismometric wave trains were calculated. The distribution of correlation coefficients and the most probable value for each period are presented in Figure 7.

It should be emphasized that in the SEN scheme, the correlation coefficients of the Black Forest gravimeter-seismometer pair (BFO.LG1-BFO.BHZ) recordings are very high (above 0.9 ) only for periods between 200 and $500 \mathrm{~s}$. For periods shorter than $200 \mathrm{~s}$, 

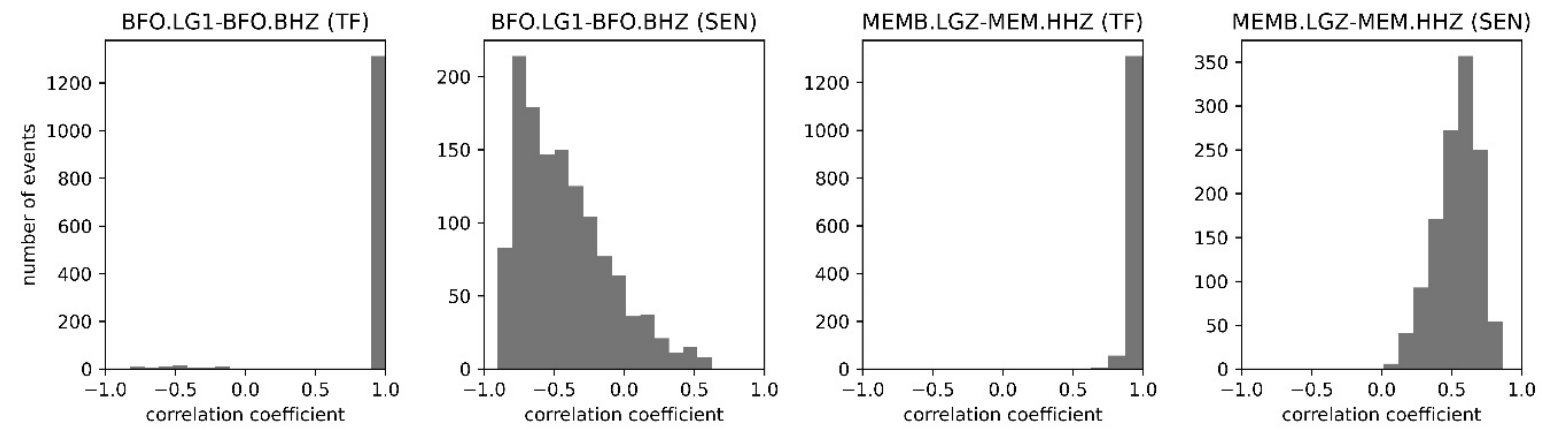

Fig. 6 Examples of histogram of correlation coefficient for the gravimeter and co-located seismometer from the Black Forest (BFO.LG1-BFO.BHZ) and Membach (MEMB.LGZ-MEM.HHZ) stations for the SEN and TF schemes.

the correlation coefficient slowly decreases to 0.6. Whereas in the TF scheme, the correlation coefficient remains at the same high level (above 0.9 ) for periods up to $500 \mathrm{~s}$. For periods above $500 \mathrm{~s}$, the correlation slowly decreases in both schemes (SEN and TF), which is related to decaying the amplitude of the signal generated by earthquakes below the noise-level threshold. A constant cross-correlation lag, equal to $10 \mathrm{~s}$, is observed in the SEN scheme in a period range of $10-800 \mathrm{~s}$, which is consistent with the time lag values presented in Figure 1b. Only for periods above $800 \mathrm{~s}$, some outliers appear due to low correlation between signals. In the TF scheme, time lag value reduces to 0 for the entire analysed period range.

Similar analysis was performed for the two gravimeter-seismometer pairs from the Membach (MEMB.LGZ-MEM.HHZ) and Rochefort (RCHS.LGZ-RCHS.HHZ) stations. The cross-correlation time lag values are consistent with values calculated from the phase of the transfer functions for periods up to about $200 \mathrm{~s}$. However, due to the lower period ranges of seismometers' operability than those of VBB seismometer (BFO.BHZ), there are apparent differences of distributions of correlation coefficient for periods exceeding $200 \mathrm{~s}$. The outliers of time lag values are observed, which are caused by the filtering range (high-passed filtered with a corner period of $120 \mathrm{~s}$ and $360 \mathrm{~s}$, respectively) and the cut-off period of seismometers.

This analysis shows that in the period range of $200-500 \mathrm{~s}$, there is a very high compatibility between the gravimetric and seismometric recordings of earthquakes, even if only the sensitivity coefficient was applied to the gravimetric recordings. Moreover, not taking into account a phase shift (or a time lag) of the gravimetric signal in the analyses of earthquake recordings will mainly affect the measurements of waves of shortest periods. The discrepancies in time may reach $50 \%$ for a period of $20 \mathrm{~s}$ and $5 \%$ for a period of $200 \mathrm{~s}$ for gravimeters with a time lag equal $10 \mathrm{~s}$.

\section{RAYLEIGH SURFACE WAVES DETERMINATION}

Determination of group velocities of Rayleigh waves enables testing the quality of earthquake recordings of individual instruments. Besides the entire signal, the signal filtered for particular periods by extracting individual wave trains can be tested. Moreover, the determination of the averaged dispersion curves makes it possible to assess the credibility of the records of individual instruments by comparing them to the synthetic curve determined based on the ak135 model (Kennett et al., 1995), which is an adequate model for the part of Europe where the stations investigated are located.

\subsection{NON-CONSTANT RELATIVE RESOLUTION FILTERING}

The first step in the analysis was isolating the fundamental-mode of Rayleigh surface waves. The procedure described by Kolínský (2004) was followed. A classical method of Fourier transform was applied in the multiple-filtering procedure, i.e., relative resolution filtering with the filter coefficient linearly dependent on a period was used (Dziewonski et al., 1969; Kolínský, 2004). One hundred Gaussian filters of central periods in the range of $10-1000 \mathrm{~s}$ were applied to generally asymmetric spectra. Therefore, the instantaneous periods were estimated (Levshin et al., 1989) and used instead of central periods.

Figure 8 shows the example of wave trains of the Bouvet Island Region earthquake (2017-10-10 18:53:33.6 UTC, $54.33^{\circ} \mathrm{S}, 8.49^{\circ} \mathrm{E}$, depth $10 \mathrm{~km}$ ) recorded at the Black Forest and Membach stations. Wave trains calculated from gravimetric and seismometric data match very well at the Black Forest station (SG gravimeter and VBB seismometer). In contrast, at the Membach station (SG gravimeter and BB seismometer), poor compliance is observed for periods greater than $100 \mathrm{~s}$. The BB seismometer from the Membach station has a cut-off period of $30 \mathrm{~s}$, and as a consequence, the wave trains for longer periods are not well reconstructed. 

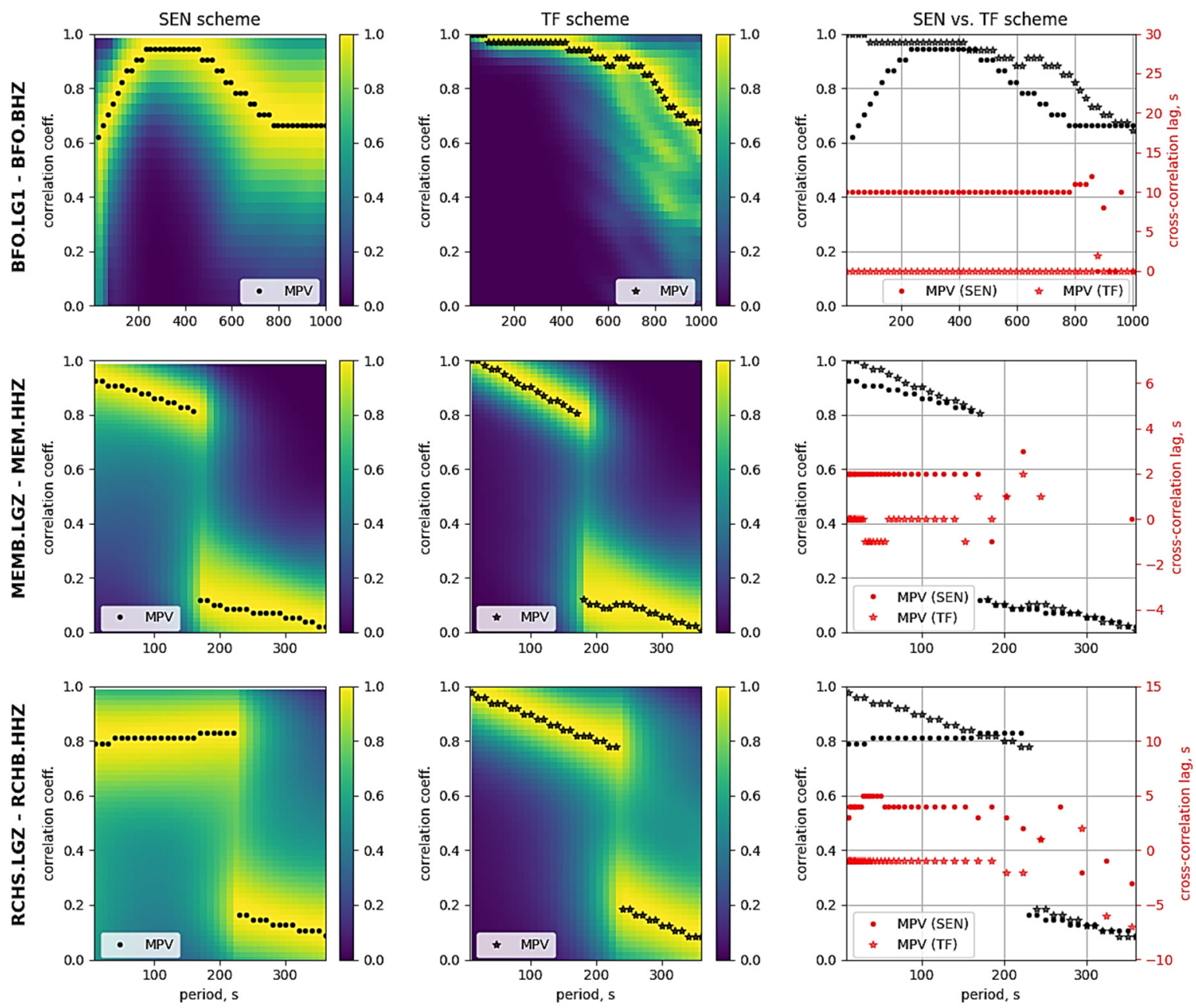

Fig. 7 Distribution of the values of coefficient of correlation between gravimetric and co-located seismometric recordings of selected strong earthquakes for the SEN and TF schemes, together with the most probable value (MPV) of correlation coefficient for each period for the Black Forest (BFO.LG1-BFO.BHZ), Membach (MEMB.LGZ-MEM.HHZ) and Rochefort (RCHS.LGZ-RCHB.HHZ) stations. Additionally, the most probable cross correlation time lag values (mode of sample) for both schemes have been presented in the right column (red colour).

\subsection{AUTOMATIC SELECTION OF INDIVIDUAL GROUP-VELOCITY DISPERSION CURVES}

The group-velocities of fundamental-mode of Rayleigh waves were measured using the procedure described by Kolínský (2004). The ak135 model of the crustal and mantle P-wave and S-wave velocities (Kennett et al., 1995) was used to validate measured dispersion curves. Two criteria described by Soomro et al. (2016) were applied for the automatic selection of group-velocities. The first criterion was a background model criterion, which is defined by the difference between the estimated group-velocity and the value calculated from the background model mentioned above for each angular frequency:

$$
\left|\frac{u\left(\omega_{i}\right)-u_{0}\left(\omega_{i}\right)}{u_{0}\left(\omega_{i}\right)}\right| \cdot 100 \%<t h_{\Delta u}
$$

where $t h_{\Delta u}$ is the maximum difference between the measured and reference group-velocity in percent
(10\% in this study), $u_{0}\left(\omega_{i}\right)$ is the group-velocity of the background model, and $u\left(\omega_{i}\right)$ is the measured group-velocity at each angular frequency $\omega_{i}$. The second criterion is based on smoothness calculation:

$$
S\left(\omega_{i}\right)=\sum_{\omega_{j}=\omega_{i}-d\left(\omega_{i}\right)}^{\omega_{i}+d\left(\omega_{i}\right)}\left|\frac{u^{\prime}\left(\omega_{j}\right)-u_{0}^{\prime}\left(\omega_{j}\right)}{u_{0}\left(\omega_{j}\right)}\right|<t h_{S},
$$

where $t h_{S}$ is a maximum value of the sum $S\left(\omega_{i}\right)$ equal $250 \mathrm{~s}, u^{\prime}\left(\omega_{j}\right)$ is the first derivative of the measured group-velocity with respect to the angular frequency, $u_{0}^{\prime}\left(\omega_{j}\right)$ is the first derivative of group-velocity calculated for a background model and $2 \cdot d\left(\omega_{i}\right)$ is the angular frequency range of the summation, which value increases with angular frequencies. A rather high value of $t h_{S}$ ('loose' criterion) was used because events were carefully selected based on signal processing and manual verification. 
(a)

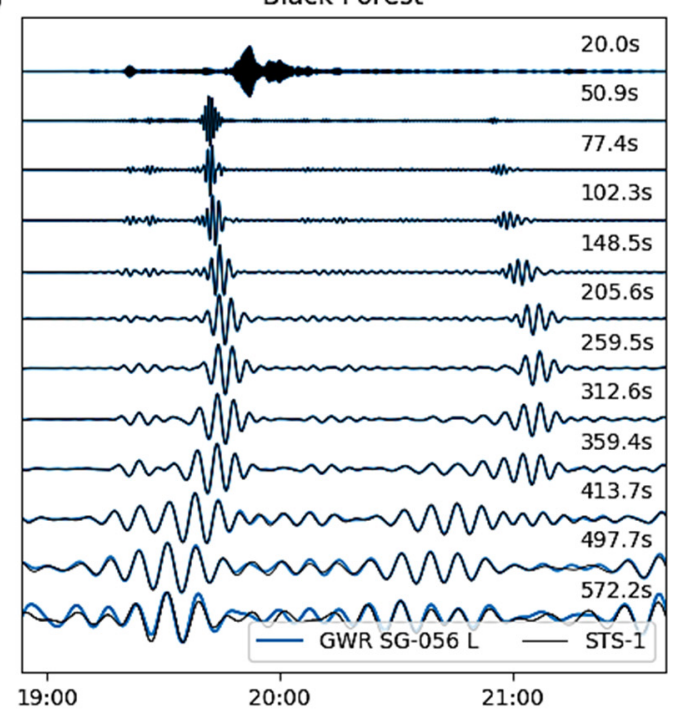

(b)

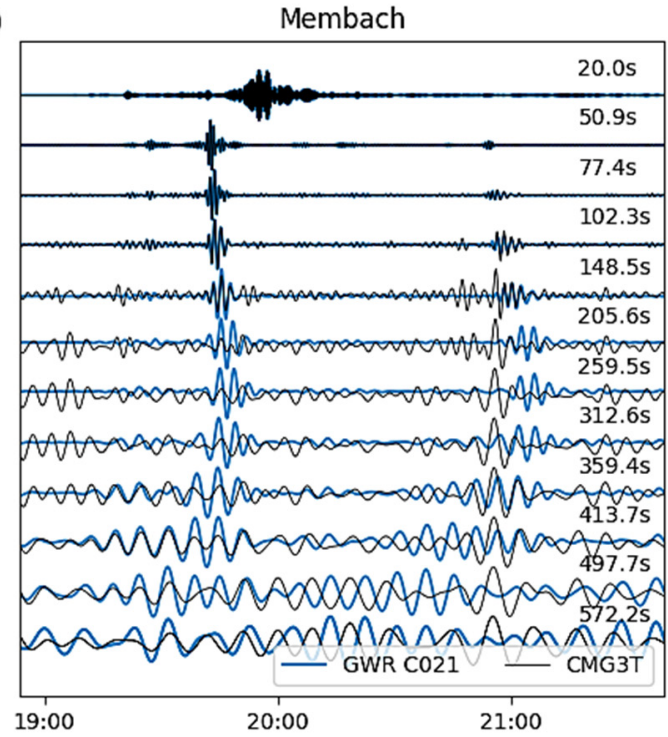

Fig. 8 Normalized wave trains of the M6.7 Bouvet Island Region earthquake recorded by a gravimeter (blue line) and co-located seismometer (black line) of the Black Forest (a) and Membach (b) stations, respectively. Central periods for selected Gaussian filters are shown on the right.

\subsection{AVERAGED GROUP-VELOCITY DISPERSION CURVES OF RAYLEIGH WAVES}

Averaged dispersion curves for all instruments were calculated from individual group-velocity dispersion curves by estimating the mean value of group-velocity for each period (solid lines in Figure 9). The standard deviation (shaded areas in Figure 9) of measured group-velocity is at the level of $0.10-0.15 \mathrm{~km} / \mathrm{s}$ for periods smaller than $60 \mathrm{~s}$ or larger than $400 \mathrm{~s}$ and $0.05-0.09 \mathrm{~km} / \mathrm{s}$ for other periods in the case of tidal gravimeters and also the VBB seismometer. For comparison, the standard deviation of group-velocity measured based on recordings of the BB $(30 \mathrm{~s})$ seismometer is at the level of 0.08 $0.09 \mathrm{~km} / \mathrm{s}$ for periods of $60-90 \mathrm{~s}$, while for other periods it is much larger, i.e., $0.10-0.15 \mathrm{~km} / \mathrm{s}$, reaching the same values like for periods above $400 \mathrm{~s}$ in the case of tidal gravimeters. All averaged dispersion curves with their standard deviation have been presented in Figure 9. The individual group-velocities of dispersion curves were selected using the automated selection method.

All estimated dispersion curves were used to create probability density distribution maps; together with the most probable value of group-velocity for each period marked by blue dots, they are shown in Figure 10. The yellow colour indicates the high probability (above 0.9 ) of particular values of groupvelocity at a given period. The differences between the mean and most probable values of velocities are well visible for periods larger than $400 \mathrm{~s}$ for SGs and the VBB seismometer (BFO.LG1, BFO.LG2, MEMB.LGZ, RCHS.LGZ, BFO.BHZ), $270 \mathrm{~s}$ for the spring gravimeter (BFO.LGZ) and $250 \mathrm{~s}$ for $\mathrm{BB}$ (120 s) seismometer (RCHB.HHZ). These differences are caused by applying the automatic selection based on the ak135 model, during which the unreliable values of group velocity compared to the reference model were rejected.

The maximum period for which it is possible to measure the group-velocity of Rayleigh waves depends on the amount of energy generated by the earthquake's source, the distance between the source and the receiver, and the type of instrument installed at the station. For instruments investigated, the reliable measurement of the Rayleigh waves' group-velocity was possible up to the period of $450 \mathrm{~s}$ for the VBB seismometer (BFO.BHZ), 400-450 $\mathrm{s}$ for the SGs (BFO.LG1, BFO.LG2, MEMB.LGZ and RCHS.LGZ), $300 \mathrm{~s}$ for the spring gravimeter (BFO.LGZ), $250 \mathrm{~s}$ for the BB (120 s) seismometer (RCHB.HHZ) and $200 \mathrm{~s}$ for the BB (30 s) seismometer (MEM.HHZ).

The presented results show an excellent consistency between dispersion curves estimated based on recordings of tidal gravimeters and the VBB seismometer from the Black Forest Observatory. All averaged dispersion curves and the differences between gravimetric and seismometric curves for each period are presented in Figure 11. Generally, dispersion curves are similar for all sites because of relatively close distances between the observatories (the largest distance between the observatories does not exceed $400 \mathrm{~km}$ ). In the case of the Membach and Rochefort stations, the differences between gravimetric and seismometric curves are related to corner periods of seismometers, which are $120 \mathrm{~s}$ for the Rochefort seismometer (Trillium Compact), and $30 \mathrm{~s}$ for the Membach seismometer (CMG-3T). Because of that, these instruments are not capable of recording periods as long as those recorded by gravimeters or the VBB seismometer. Also, the 
(a)

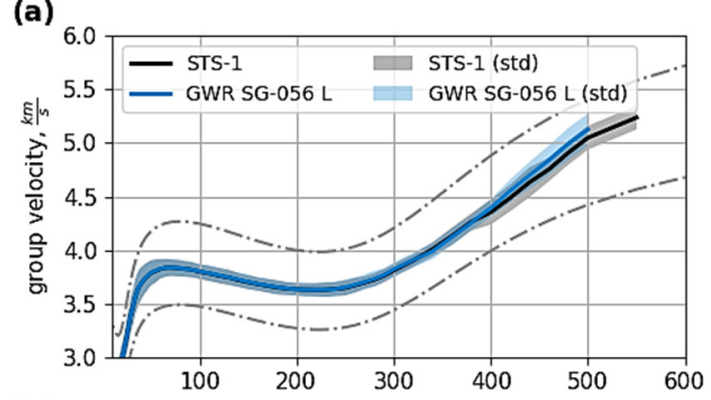

(c)

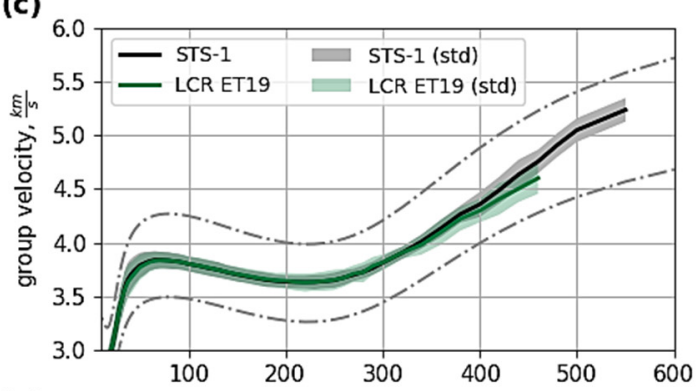

(e)

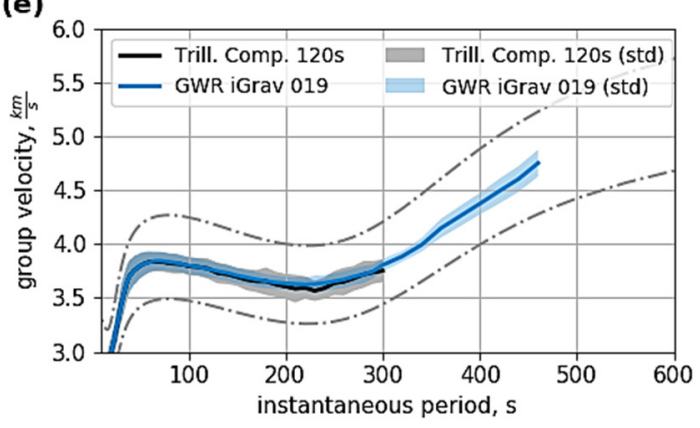

(b)

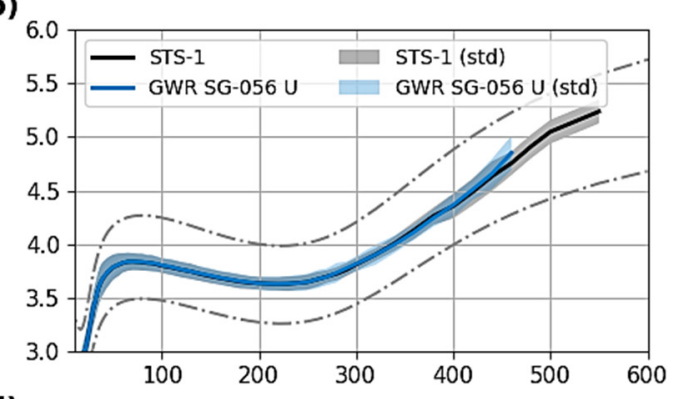

(d)

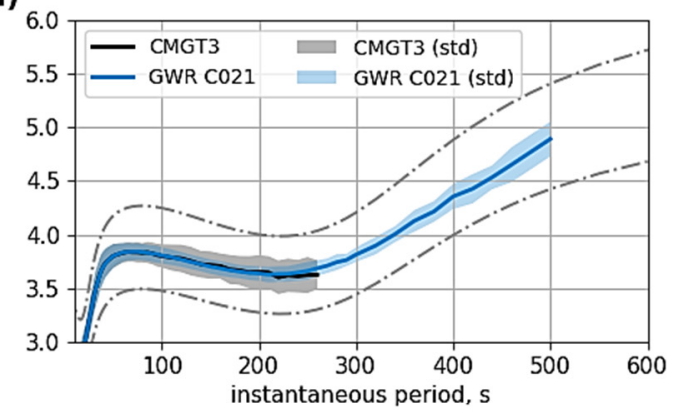

Fig. 9 Averaged dispersion curves of group-velocity of fundamental-mode of Rayleigh waves (solid lines) with the standard deviation of individual measurements (shaded areas) as well as with minimum and maximum value of the background model (dash-dotted grey lines) for each instrument of the Black Forest (a, b, c), Membach (d) and Rochefort (e) observatories.
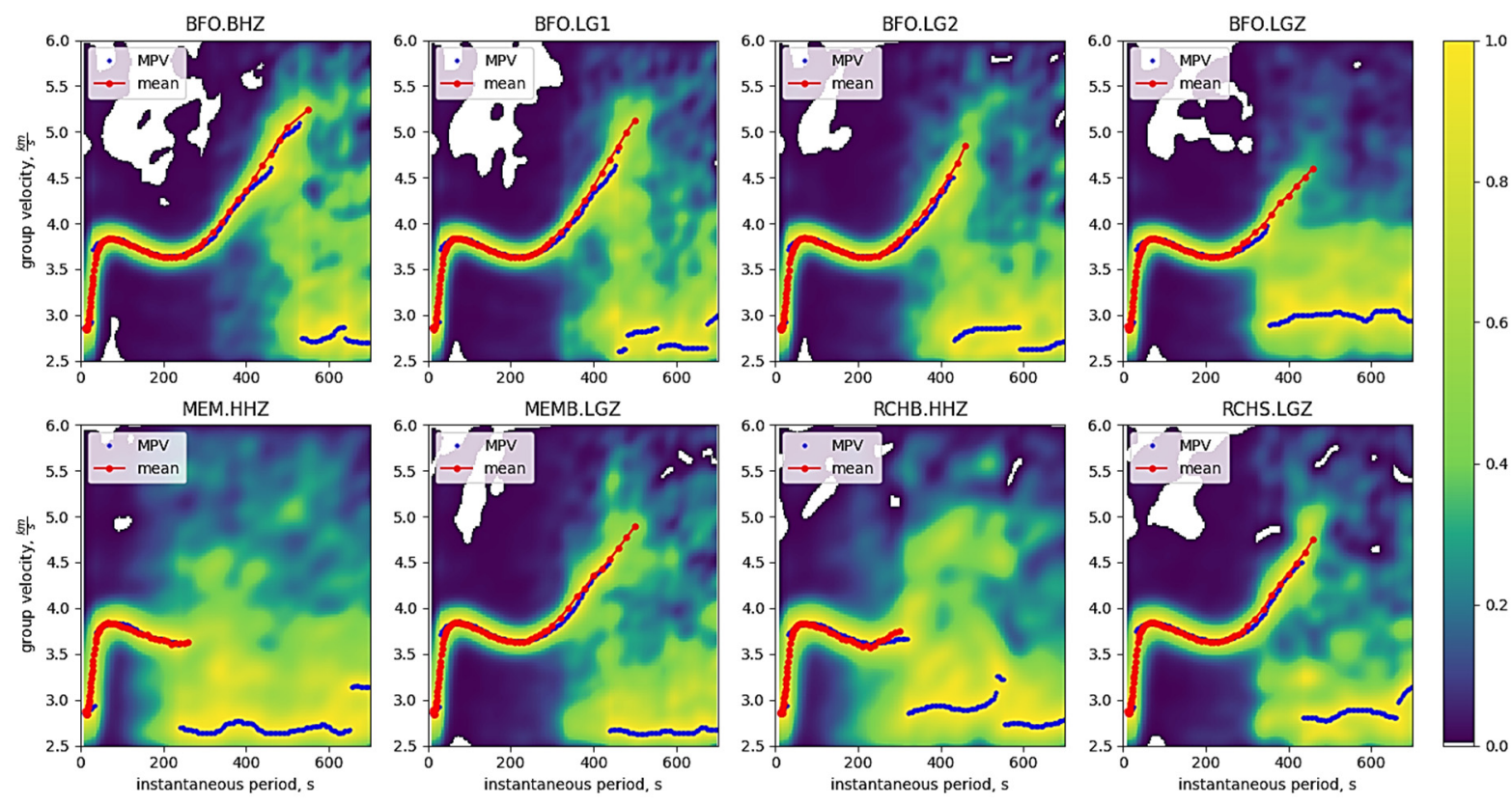

Fig. 10 Probability density distribution maps of group-velocity of fundamental-mode of Rayleigh waves together with the most probable values (blue dots) and averaged values (solid red line with dots) for each investigated instrument of the Black Forest, Membach and Rochefort stations. 

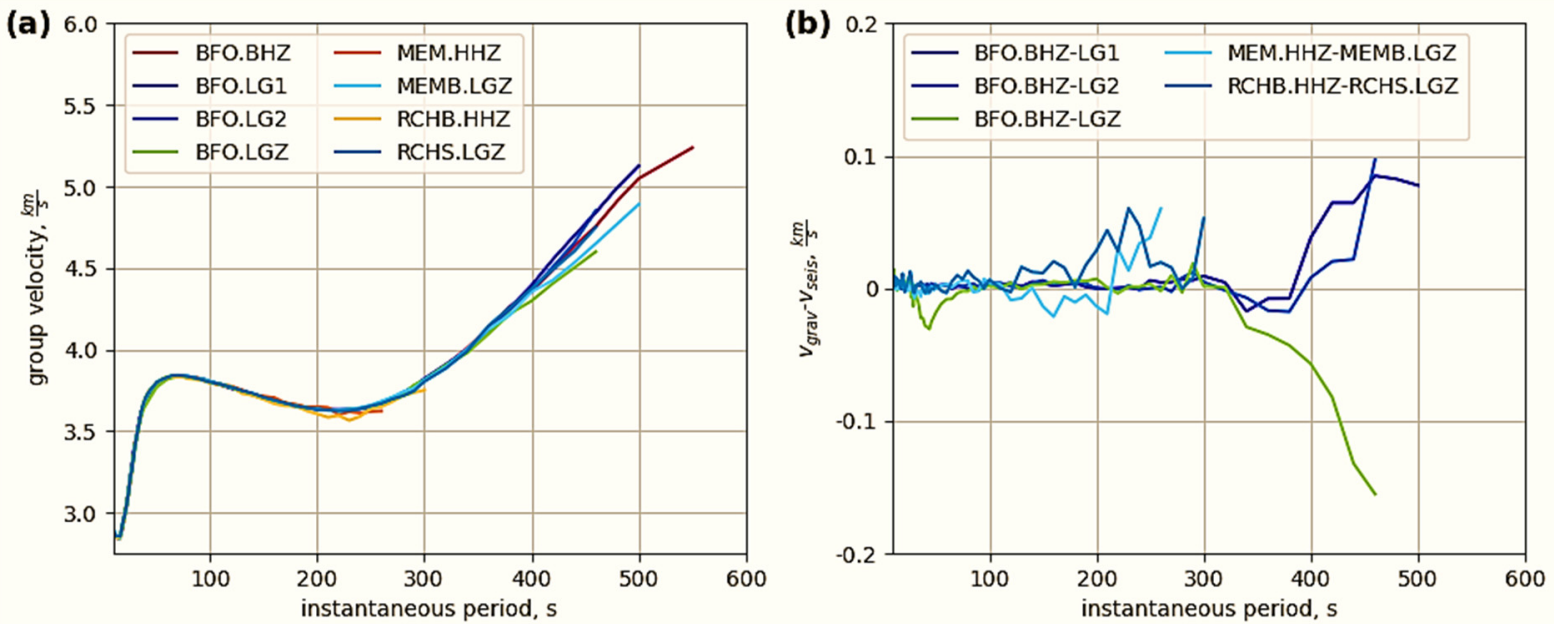

Fig. 11 Averaged dispersion curves of group-velocity of fundamental-mode of Rayleigh waves (a) and the differences between gravimetric and seismometric curves for each period (b) for investigated instruments from the Black Forest, Membach and Rochefort stations.

Table 3 Minimum and maximum discrepancies between the observed and theoretical (ak135 model) values of Rayleigh waves group-velocities for the gravimeter and co-located seismometer of the Black Forest, Membach and Rochefort stations.

\begin{tabular}{|c|c|c|c|c|c|c|c|c|}
\hline IRIS code & $\begin{array}{l}\text { BFO. } \\
\text { BHZ }\end{array}$ & $\begin{array}{r}\text { BFO. } \\
\text { LG1 }\end{array}$ & $\begin{array}{r}\text { BFO. } \\
\text { LG2 }\end{array}$ & $\begin{array}{r}\text { BFO. } \\
\text { LGZ }\end{array}$ & $\begin{array}{r}\text { MEM. } \\
\text { HHZ }\end{array}$ & $\begin{array}{r}\text { MEMB. } \\
\text { LGZ }\end{array}$ & $\begin{array}{r}\text { RCHB. } \\
\text { HHZ }\end{array}$ & $\begin{array}{r}\text { RCHS. } \\
\text { LGZ } \\
\end{array}$ \\
\hline Min & $-4.7 \%$ & $-4.5 \%$ & $-4.6 \%$ & $-4.2 \%$ & $-4.0 \%$ & $-3.8 \%$ & $-4.6 \%$ & $-4.3 \%$ \\
\hline Max & $3.2 \%$ & $4.3 \%$ & $2.1 \%$ & $0.5 \%$ & $0.9 \%$ & $0.9 \%$ & $1.0 \%$ & $1.0 \%$ \\
\hline
\end{tabular}

group-velocities measured based on the LCR ET-19 spring gravimeter recordings, in the range of 30-60 s, have lower values compared to the other Black Forest instruments. Amplitudes and phases of the LCR ET- 19's transfer function show some distortion in this period range, which might cause the observed deviation (see Fig. 1). The comparison of the estimated values of group-velocity of the gravimeters and seismometers with respect to the ak135 model is summarized in Table 3.

\section{DISCUSSION AND CONCLUSIONS}

The present study shows that the recordings of earthquakes by the tidal gravimeters and co-located VBB and BB seismometers correspond very well in the period ranges of instruments' operability. This is because the transfer function of instruments is accordingly removed during the pre-processing of data. That observation was confirmed by analysing almost 6,300 coefficients of correlation between gravimetric and co-located seismometric recordings of an earthquake and the distribution of the maximum values of the recorded acceleration. It has been demonstrated that the estimated mode of a sample of cross-correlation coefficients are 0.94 at least and SG signals saturate when the amplitudes of earthquakes exceed: $\pm 0.9 \cdot 10^{4} \mathrm{~nm} / \mathrm{s}^{2}$ (BFO.LG1) and $\pm 1.5 \cdot 10^{4} \mathrm{~nm} / \mathrm{s}^{2}$ (BFO.LG2, MEMB.LGZ and RCHS.LGZ).

The most appropriate way of the pre-processing data by band-pass filtering without applying tidal and atmospheric pressure corrections was proposed. That was confirmed by analysing probabilistic power spectral density of recordings of instruments of the highest quality, the GWR SG-056 (lower sphere) gravimeter and the VBB (STS-1) seismometer, located at a very quiet site at the Black Forest Observatory. Obviously, for other sites and instruments of lower or comparable quality, those conclusions will also be valid. Additionally, the detailed analysis of wave trains with central periods between 10 and $1000 \mathrm{~s}$, calculated based on the GWR SG-056 (lower sphere) and the VBB (STS-1) recording of strong earthquakes, had shown that for periods longer than $200 \mathrm{~s}$, there is a high compatibility between the gravimetric and seismometric recording, when only the sensitivity coefficient was applied to the gravimetric recordings. But a time lag value of the signal must be taken into consideration during the analysis of earthquake recordings. In the period range of 10-200 s, the full transfer function of the gravimeter should be removed during the pre-processing scheme to analyse the gravimetric recordings of an earthquake. Filtering in the range of 2-1000 s was also tested, but resulted in numerical errors in the case of the Black Forest gravimeters due to the characteristics of the instruments.

The proposed procedure of pre-processing of earthquake recordings of the tidal gravimeters is in line with the results obtained by other authors, in particular in terms of not applying the atmospheric 
pressure corrections in the period range of $10-1000 \mathrm{~s}$ (see Banka and Crossley, 1999; Freybourger et al., 1997; Zürn and Meurers. 2009; Van Camp et al., 2017). However, the full transfer function of gravimeters or at least the sensitivity coefficient/calibration factor and the time lag value must be taken into consideration when the earthquake recordings are analysed, especially for periods shorter than 200 s. Some authors, e.g. Li et al. (2020) have claimed that it is not justified to apply a transfer function of gravimeter into a processing scheme of earthquake recordings. But the analysis presented in this study has shown that such approach is not correct.

Furthermore, the comparison of the group-velocity dispersion curves of the fundamental mode of Rayleigh waves estimated in the period range of 10-1000 s from the recordings of tidal gravimeter and co-located typical BB seismometers (CMG3T-30s, Trillium Compact-120s) shows that gravimetric data can complement seismic recordings for periods higher than 100-180 s, depending on seismometer' characteristics. The greatest advantage of tidal gravimeters is their ability to record long period seismic waves without distortion (the flat amplitude transfer function. As a consequence, when the observatory is not equipped with a BB seismometer, a tidal gravimeter, especially a superconducting one, can act as a vertical component of VBB seismometer for periods higher than $10 \mathrm{~s}$. Averaged dispersion curves were estimated based on gravimetric and seismometric data for events worldwide (global scale) and match very well to each other for each site. The standard deviation of averaged measurements varies in the range of $0.05-0.15 \mathrm{~km} / \mathrm{s}$. Comparison of the estimated averaged values of group-velocity of gravimeters and seismometers with respect to the PREM model shows that discrepancies of the observed and the theoretical values are between $-3.1 \%$ and $4.6 \%$ (for periods greater or equal $120 \mathrm{~s}$ ).

Presented results are similar to those obtained recently by $\mathrm{Li}$ et al. (2020). They have extracted long-period surface waves and background free oscillations (Earth's hum) based on the ambient noise data of seven global distributed SGs and three collocated VBB (STS-1) seismometers. The gravimetric and seismometric data are pre-processed by (1) removing earthquake recordings based on the earthquake catalogue; (2) converting the gravimetric (taking into account the sensitivity coefficient) and seismometric (after removing the transfer function) data to $\mathrm{nm} / \mathrm{s}^{2}$ and air pressure data to $\mathrm{hPa}$, respectively; (3) removing the atmospheric pressure effect by the standard coefficient of $-3.0 \mathrm{~nm} / \mathrm{s}^{2} / \mathrm{hPa}$ and high-pass filtering with the corner period of $5000 \mathrm{~s}$. The groupvelocity dispersion curves are measured for all the instruments in the period range of 120-1000 s (1minute sampling data were analysed). The comparison of the estimated values of group-velocity of the gravimeters and seismometers with respect to the PREM model shows that discrepancies of the observed and the theoretical values are between $-4 \%$ and $4 \%$. The standard deviations values vary up to the
$0.16 \mathrm{~km} / \mathrm{s}$ and are almost the same, i.e. 0.01$0.04 \mathrm{~km} / \mathrm{s}$, at the period range of $140-333 \mathrm{~s}$ for most analysed sensors.

This study presents first such comprehensive approach to earthquake records made by a tidal gravimeter. It can be concluded that recordings of earthquakes in the period range of 10-1000 s by tidal gravimeters are very reliable when the full transfer function of instruments is taken into account during the signal analysis. Moreover, the simple processing scheme consisting of band-pass filtering can be adopted, with no need for applying the tidal and local atmospheric pressure corrections. What's more, based on gravimetric recordings of fundamental mode of Rayleigh waves, the structure of the mantle can be determined for greater depths than from the recording of typical broad-band seismometers.

\section{ACKNOWLEDGEMENTS}

The ObsPy package was used for data processing (Krischer et al., 2015). All visualizations were made with the use of Matplotlib library (Hunter, 2007). The facilities of IRIS Data Services, and specifically the IRIS Data Management Center, were applied for accessing waveforms (seismic data and gravimetric data from the Black Forest, Membach and Rochefort stations), related metadata, and/or derived products used in this study. IRIS Data Services are funded through the Seismological Facilities for the Advancement of Geoscience and EarthScope (SAGE) Proposal of the National Science Foundation under Cooperative Agreement EAR-1261681. The list of earthquakes was downloaded from the European Mediterranean Seismological Centre bulletin (https://www.emsc-csem.org/Earthquake/). The authors are grateful to Duncan Agnew and Jan Krynski for valuable comments and suggestions, which helped to improve the article. This work was done within the research project No. 2017/27/B/ST10/01600 financed from the funds of the Polish National Science Centre.

\section{REFRENCES}

Agnew, D., Berger, J., Farrell, W., Gilbert, F., Master, G. and Miller, D.: 1986, Project IDA: A decade in review. Eos Trans. AGU, 67, 203-212.

Banka, D. and Crossley, D.: 1999, Noise levels of superconducting gravimeters at seismic frequencies. Geophys. J. Int., 139, 87-97. DOI: 10.1046/j.1365-246X.1999.00913.x

Beauduin, R., Lognonné, P., Montagner, J.P., Cacho, S., Karczewski, J.F. and Morand, M.: 1996, The effects of the atmospheric pressure changes on seismic signals or how to improve the quality of a station. Bull. Seismol. Soc. Am., 86, 6, 1760-1769. DOI: $10.1785 / \mathrm{BSSA} 0860061760$

Berger, J., Agnew, D.C., Parker, R.L and Farrell, W.E.: 1979, Seismic system calibration: 2. Cross-spectral calibration using random binary signals. Bull. Seismol. Soc. Am., 69, 271-288.

Bos, M.S. and Scherneck, H.-G.: 2021, Ocean tide loading provider. Onsala Space Observatory, http://holt.oso.chalmers.se/loading/. 
Dziewonski, A., Bloch, S. and Landisman, M.: 1969, A technique for the analysis of transient seismic signals. Bull. Seismol. Soc. Am., 59, 427-444.

Forbriger, T., Zuern, W. and Widmer-Schnidrig, R.: 2021, Challenges and perspectives for lowering the verticalcomponent long-period detection level. Seismol. Res. Lett., 92, 4, 2498-2512. DOI: 10.1785/0220200399

Francis, O., Lampitelli, C., Klein, G., Van Camp, M. and Pálinkáš, V.: 2011, Comparison between the Transfer Functions of three Superconducting Gravimeters. Marées Terrestres Bulletin d'Informations, 147, 11857-11868.

Freybourger, M., Hinderer, J. and Trampert, J.: 1997, Comparative study of superconducting gravimeters and broadband seismometers STS-1 / Z in seismic and subseismic frequency bands. Phys. Earth Planet. Inter., 101, 203-217. DOI: 10.1016/S0031-9201(97)00003-4

Hunter, J.D.: 2007, Matplotlib: A 2D graphics environment. Comput. Sci. Eng. 9, 90-95. DOI: 0.1109/MCSE.2007.55

Kamal, Mansinha, L.: 1992, A test of the superconducting gravimeter as a long-period seismometer. Phys. Earth Planet. Inter., 71, 52-60. DOI: $10.1016 / 0031-9201(92) 90028-\mathrm{T}$

Kanamori, H. and Given., J.W.: 1981, Use of long-period surface waves for fast determination of earthquake source parameters. Phys. Earth Planet. Inter., 27, 8-31.

Kennett, B.L.N., Engdahl, E.R. and Buland, R.: 1995, Constraints on seismic velocities in the earth from travel times. Geophys. J. Int., 122, 1, 108-124. DOI: $10.1111 / \mathrm{j} .1365-246 X .1995 . t b 03540 . x$

Kolínský, P.: 2004, Surface waves dispersion curves of Eurasian earthquakes: The SVAL program. Acta Geodyn. Geomater., 1, 2(134), 165-185.

Krischer, L., Megies, T., Barsch, R., Beyreuther, M., Lecocq, T., Caudron, C. and Wassermann, J.: 2015, ObsPy: A bridge for seismology into the scientific Python ecosystem. Comput. Sci. Discov, 8, 014003. DOI: 10.1088/1749-4699/8/1/014003

Levshin, A.L., Yanovskaya, T.B., Lander, A.V., Bukchin, B.G., Barmin, M.P., Ratnikova, L.I and Its, E.N.: 1989, Recording, identification, and measurement of surface wave parameters - frequency-time analysis. In: Seismic Surface Waves in a Laterally Inhomogeneous Earth, Keilis-Borok, V.I. (Ed.). DOI: 10.1007/978-94-009-0883-3 5

Li, H., Xu, J., Chen, X., Sun, H., Zhang, M. and Zhang, L.: 2020, Extracting long-period surface waves and free oscillations using ambient noise recorded by Global Distributed Superconducting Gravimeters. Seismol. Res. Lett., 20, 1-13. DOI: 10.1785/0220190166

Masters, G., Jordan, T., Silver, P. and Gilbert, F.: 1982, Aspherical Earth structure from fundamental spheroidal-mode data. Nature, 298, 609-613. DOI: $10.1038 / 298609 \mathrm{a} 0$

McNamara, D.E. and Buland, R.P.: 2004, Ambient noise levels in the continental United States. Bull. Seismol. Soc. Am., 94, 4, 1517-1527. DOI: $10.1785 / 012003001$

Nakanishi, I. and Anderson, D.L.: 1982, Worldwide distribution of group velocity of mantle Rayleigh waves as determined by spherical harmonic inversion. Bull. Seismol. Soc. Am., 72, 4, 1185-1194. DOI: $10.1785 /$ BSSA0720041185

Niebauer, T., MacQueen, J., Aliod, D. and Francis, O.: 2011, Monitoring earthquakes with gravity meters. Geod. Geodyn., 2, 71-75,

DOI: $10.3724 /$ sp.j.1246.2011.00071.2
Peterson, J.: 1993, Observations and modeling of seismic background noise. U.S. Geological Survey, Open-File Report, 93-322. DOI: 10.3133/ofr93322

Richter, B., Wenzel, H., Zürn, W. and Klopping, F.: 1995, From chandler wobble to free oscillations: comparison of cryogenic gravimeters and other instruments in a wide period range. Phys. Earth Planet. Inter., 91, 1, 131-148. DOI: 10.1016/0031-9201(95)03041-T

Rosat, S., Hinderer, J., Crossley, D. and Boy, J.P.: 2004, Performance of superconducting gravimeters from long-period seismology to tides. J. Geodyn., 38, 461476. DOI: $10.1016 / j$.jog.2004.07.005

Rosat, S., Sato, T., Imanishi, Y., Hinderer, J., Tamura, Y., McQueen, H. and Ohashi, M.: 2005, High-resolution analysis of the gravest seismic normal modes after the $2004 \mathrm{Mw}=9$ Sumatra earthquake using superconducting gravimeter data. Geophys. Res. Lett., 32, L13304. DOI: 10.1029/2005GL023128

Rosat, S. and Hinderer, J.: 2011, Noise levels of Superconducting Gravimeters: Updated comparison and time stability. Bull. Seismol. Soc. Am., 101, 3, 1233-1241. DOI: 10.1785/0120100217

Rosat, S. and Hinderer, J.: 2018, Limits of detection of gravimetric signals on Earth. Scientific Reports, 8, 15324. DOI: $10.1038 / \mathrm{s} 41598-018-33717-\mathrm{z}$

Schueller, K.: 2019, Theoretical basis for Earth tide analysis and prediction. Manual-01-ET34-X-V72, Surin.

Soomro, R.A., Weidle, C., Cristiano, L., Lebedev, S. and Meier, T.: 2016, Phase velocities of Rayleigh and Love waves in central and northern Europe from automated, broad-band, interstation measurements. Geophys. J. Int., 204, 1, 517-534. DOI: $10.1093 / \mathrm{gji} /$ ggv462

Tamura Y.: 1987, A harmonic development of the tidegenerating potential. Bulletin d'Informations des Marées Terrestres, 99, 6813-6855.

Van Camp, M.: 1999, Measuring seismic normal modes with the GWR C021 superconducting gravimeter. Phys. Earth Planet. Inter., 116, 81-92. DOI: 10.1016/S0031-9201(99)00120-X

Van Camp, M., Wenzel, H.G., Schott, P., Vauterin, P. and Francis, O.: 2000, Accurate transfer function determination for superconducting gravimeters. Geophys. Res. Lett., 27, 37-40. DOI: 10.1029/1999GL010495

Van Camp, M., Steim, J., Rapagnani, G. and Rivera, L.: 2008, Connecting a Quanterra Data Logger Q330 on the GWR C021 Superconducting Gravimeter. Seismol. Res. Lett., 79, 6, 785-796. DOI: $10.1785 / \mathrm{gssrl} .79 .6 .785$

Van Camp, M., de Viron, O., Watlet, A., Meurers, B., Francis, O. and Caudron, C.: 2017, Geophysics from terrestrial time-variable gravity measurements. Rev. Geophys., 55, 938-992. DOI: $10.1002 / 2017 R G 000566$

Wenzel, H.-G.: 1994, Accurate instrumental hase lag determination for feedback gravimeters. Bulletin d'Informations des Marées Terrestres, 118, 87358752.

Widmer-Schnidrig, R.: 2003, What can superconducting gravimeters contribute to normal-mode seismology? Bull. Seismol. Soc. Am., 93, 1370-1380. DOI: $10.1785 / 0120020149$

Zürn, W. and Meurers, B.: 2009, Clear evidence for the signreversal of the pressure admittance to gravity near 3mHz. J. Geodyn., 48, 3-5, 371-377.

DOI: 10.1016/j.jog.2009.09.040 